\title{
Study on Requirements of Usability of Web Service-Based Enterprise Information Systems*
}

\author{
Shuangyuan Shi, Shuqin Cai, Zhonghui Li
}

Huazhong University of Science and Technology, Wuhan, China.

Email: shisy@mail.hust.edu.cn, caishuqin@sina.com,lzhspace@gmail.com

Received September $14^{\text {th }}, 2011$; revised October $9^{\text {th }}, 2011$; accepted October $20^{\text {th }}, 2011$

Copyright (C) 2013 Shuangyuan Shi et al. This is an open access article distributed under the Creative Commons Attribution License, which permits unrestricted use, distribution, and reproduction in any medium, provided the original work is properly cited.

\begin{abstract}
With the trend of economic globalization and localization services, employees are distributed in different regions, the old enterprise information system in closed environment has been difficult to support all the business in enterprises, also cannot meet the need of information sharing between upstream and downstream enterprises and partners in the supply chain. The new business model requires companies to have distributed information systems, remote access and other characteristics. VPN (virtual private network) is high cost and lack of flexibility, Web services-based information system can achieve low-cost real-time collection to process and share distributed information, which is the ideal model of enterprise information system. However, there is a big gap in current usability between the Web services and old desktop applications. This paper combines the usage patterns, business needs of enterprise information systems and technical characteristics of Web services, proposes the usability requirements of enterprise information systems based on Web services from different views of internal users, external customers and strategic partners.
\end{abstract}

Keywords: Enterprise Development; Usability; Web Services; Enterprise Information System

\section{Introduction}

Web information systems can overcome the barriers of time and space, realize the integration of resources across sectors and achieve cross-regional, cross-enterprise information delivery, resource sharing. Therefore, enterprise information systems should be upgraded from the desktop-based applications to the Web service model. Under the support of Web 2.0 technology with the core of Ajax, the network is no longer confined to corporate information release, and has been widely used to handle customer transactions under the B2C model [1], it can better meet the needs of B2B business processing in supply chain, the exchange of information and resource sharing between enterprises. With the expanding scale and increasing functionality of Web information systems, the users' dependence on the Web services is growing and demands on the availability are increasing [2]. The usability of management information systems based on Web services has become the key to successful application of information systems [3].

"Humanities and Social Science Research Project of the Ministry of Education of China (Item Number: 11YJA630098).

National Natural Science Foundation of China: (Item Number: 71071066).
The current research of usability is focused on the guidelines and evaluation of sites. Nielsen proposed five evaluations in 1993: interactive efficiency, ease of use, ease of memory, fault tolerance and user satisfaction [1]. After that, Nielsen further put forward ten usability heuristic evaluations [4]. Sherry Y. Chen and Robert D. Macredie (2005) studied applied heuristic evaluation to examine the usability of current electronic shopping, and this study is applied to develop a set of usability guidelines to support the future design of effective interfaces for electronic shopping [5]. Jonathan W. Palmer studied the usability of B2C Web sites from five areas: downloading delay, navigation settings, interactivity, responsiveness, and information content, proposed that site design should provide users with personalized services, and can interact with the site and the site should response to the users timely [6]. Alistair Sutcliffe considered usability from the perspective of aesthetics, which will change the variables attracting users into the operational variables and do heuristic evaluation of the sites' usability and attractiveness [7]. These are many analyses of the usability of the portal and library information systems. In the usability of enterprise information systems, researchers carried on a survey on enterprise users based on usability 
guidelines. Fethi Calisira, Ferah Calisirb [8] and others studied the usability, effectiveness and ease of use of user interface to make sure that they affect users' satisfaction and influence the factors to ERP/IS systems. Through surveying the users' background, the host organization and the ERP system coverage the respondents' satisfaction to systematically survey, including the six characteristics of interface usability: system capabilities, compatibility, adaptability, user guide, ease of learning, memory minimum load, also the effectiveness of evaluation and the ease of use. Ritu Agarwal and Viswanath Venkatesh [3] did a heuristic evaluation to the content, ease of use, promotional marketing, personalization, emotional factors of corporate Web sites in 4 different sectors with task-driven approach. In the evaluation, they use an expert evaluation method and a user survey to analyze the relative importance of all the content of usability guide to guide the interaction design of information systems. Michael Pearson and Ann Pearson used a user survey to do their research, they think that ease of use is the most important factor for users [9]. Fethi Calisir and Ferah Calisir's research results show that the effectiveness and ease of learning are the determinants of enduser's satisfaction with the ERP systems, while noting that a good user guide affects on the usefulness and ease of learning [8]. Michael Pearson and Ann Pearson believe that ease of use is the most important factor for users [9]. But Ritu Agarwal and Viswanath Venkatesh's survey show that content is most important to information system users, ease of use followed, emotional factors will be subject to the mutual influence of the task and products [3]. As the survey methods and objects differ, the evaluation of the usability of information system does have some differences, indicating that the studies on usability of enterprise information system not only analyze site, or only study the users of enterprise websites, we need to analyze it from a more comprehensive perspective, to guide the design of Enterprises Web Information System.

On the other hand, although the companies understand the relevant knowledge of usability, in the process of designing information systems, the degree of related personnel's attention to usability and the usability guide is not ideal. The reasons are: 1 ) The usability is not subject to information system owners and developers' attention. 2) Neglecting the differences between information systems and websites, the existing usability guide of Web sites has its limitations, the guiding role to information systems is not enough. This paper argues that the usability of Web information systems is different from general Websites, the user community is more wide. Enterprise Web information systems not only need to meet the individual customers outside the enterprise and internal employees, but also investors. Even strategic business partners (suppliers, distributors and other upstream and downstream enterprises) need to do the information tran- sfer and business processes between enterprises through Web information systems. The different users' usability requirements of Web information system are different. The study of its usability should be adjusted accordingly. This article considers different objectives of different enterprise information system user groups, analyzes the requirements for usability, and studies the differences and contacts in usability between desktop information systems and Web-based information systems. We want to provide guidance for the usability design from a more comprehensive perspective, and to make Web information systems meet the needs of all users.

\section{The Usability and Content of Web Services}

The usability in International Standard ISO9241-11 is defined as the effectiveness, efficiency and subjective satisfaction when a particular user using a particular product with a specific task to complete in certain circumstances. For Websites, usability refers to whether the users are easy to understand how to interact with the sites, whether they can more easily find the information they need or complete the task they want to do and get an enjoyable experience from it. Currently, the studies of Web services usability are mainly about websites and personal computing, Web service usability can be divided into 7 categories, which involves the following issues:

1) Content, including related degree of the information, the depth and breadth of the content, the multimedia and timeliness of using the content.

2) Ease of use, including the site's organizational structure, as the navigation structure is easy to understand, the page-level is clear. Operation prompt is clear and convenient. Contribute to the completion of users' goals.

3) Interaction, the two-way transmission of information between the Web and the browsers, including users' feedback in usability (Feedback) and sites' response to users' questions (FAQ).

4) Personalized, the ability of meeting the needs of individual users.

5) Fault tolerance, including error prevention and recovery. Warning of error message before the IS release, as well as removing the impact caused by wrong operation.

6) User's guide, refer to whether the document can help the users and easy to find and use for users.

7) Emotional factors and the brand, which is a result of the usability design' comprehensive affect, but it is an important factor of the usability of IS.

\section{Usability Requirements of Enterprise Web Services}

Usability is based on three unstable variables: users, users' needs (objectives) and users' background [10]. The 
direct effect of different user groups is the different designs of system. Enterprise information system users can be divided into external users, internal employees, strategic partners and system owner.

Web information system users with different purposes have different needs in availability, as shown in Table 1. Facing heterogeneous users, companies need to learn the behaviors of consumers by investigating and designing attractive websites [11]. In the personalized service, use the Web service to provide better service. IS's internal users are corporate employees that growing under the same corporate culture and regulation. In the premise of meeting the functional requirements, it's more conducive to the improvement of employees' productivity. Investors will ignore emotional factors, looking forward to revenue from this investment. For the strategic partners, information transmission capacity between IS can bring the best interest to them.

\subsection{Users outside the Enterprise}

There are heterogeneous users with different life and cultural backgrounds outside the enterprises. What kinds of corporate Websites features are attractive to new users and how to maintain old customers by effective functions are the points of usability research.

Content is first noticed by users, it is the key factor to attract users in a short period of view. Content usability include: the relevance of the information, timeliness, layout, readability, use of media and so on.

Interactivity here refers to the interactive network, the feature of the direct two-way communication between the audience and the communicator or the audience and the audience in a certain extent called network interactivity, including the timely feedback on user information, meeting the needs of individual users.

Ease of use. For ordinary users, they are not familiar with the operating specifications of corporate website, so designing clear navigation systems, specific language tips, simple operation and readable error pages all reflect the usability of websites.

Personalization, Google has done very well in meeting the individual needs, as providing users with lots of customized services, greatly enhancing the usability and user experience. In corporate websites, the same should be done as an important means to attract and micro clients.

\subsection{Internal Staff}

Network makes enterprises get rid of the restrictions of time and space, and brings changes to the staff work, for example, the change of orders. Receiving orders realtime from manufacturers' collection to distributed ones in the network, staff also need to adapt to some new changes to face information systems in new model. Employees are the recipients of information systems, they differ from consumers because consumers can choose any more attractive websites for different aesthetics. But there is sufficient evidence that computers in the workplace tend to increase the number of risk factors, such as repetitive stress injuries, stress-related physical and mental disorders, the negative impact of software technology can not be ignored [10]. Therefore, high usability design of IS products is particularly important to staff.

In information system, the traditional desktop management information system based on C/S (Client/Server) mode has the advantages as system stability, rapid response business processing, data security and so on. B/S (Browser/Server) mode needn't to install the terminal software, and can support remote application and multibranch cross-platform application, database security is also considerably ensured. Especially in supply chain, such as procurement management, dynamic inventory management, customer relationship management, marketing systems, etc., the application of $\mathrm{B} / \mathrm{S}$ mode can improve the information transmission, information sharing and the efficiency of transaction processing.

The internal staff's requirements of usability can exclude some of the external and internal factors though optimizing business processes, training employees to understand the process of Web information systems operations, which means that major obstacles in employees operating IS do not exist. Table 2 Compares the advantages and disadvantages between desktop information systems and Web information systems in usability, hoping to provide guidance for the design in system development phase, make the usability of Web information systems better than desktop system.

The representation of staff's usability requirements is mission driven, they are more concerned about the system's ease of use, the degree of difficulty accessing to information and the transaction efficiency. With the development of Ajax, Web-based IS has been greatly en-

Table 1. Web service usability requirements.

\begin{tabular}{cl}
\hline Role & Demand (target) \\
\hline Internal staff & Information technology to improve efficiency, reduce errors, reduce the burden. \\
Strategic Partners & Effective communication and resource sharing to reduce risk. \\
System Investors & Attract the target groups, service users and maintain good customer relations. Establish a good corporate image. \\
External users & Information search, FAQ (Frequently Asked Questions), requiring simple operation, to meet individual needs. \\
\hline
\end{tabular}


Table 2. The comparison in usability between desktop application and Web application.

\begin{tabular}{|c|c|c|c|c|c|}
\hline \multirow{2}{*}{\multicolumn{2}{|c|}{ usability System Features }} & \multicolumn{2}{|c|}{ Desktop Information System (C/S) } & \multicolumn{2}{|c|}{ Web Information Systems (B/S) } \\
\hline & & Advantages & Disadvantages & Advantages & Disadvantages \\
\hline Lo & ig speed & Fast & $\begin{array}{l}\text { the server in heavy load under } \\
\mathrm{C} / \mathrm{S} \text { mode, the event delay }\end{array}$ & $\begin{array}{l}\text { Ajax asynchronous transfer } \\
\text { technology to reduce the } \\
\text { burden on the server }\end{array}$ & $\begin{array}{l}\text { Interactive speed is } \\
\text { limited by the server, } \\
\text { network bandwidth }\end{array}$ \\
\hline \multirow{4}{*}{$\begin{array}{l}\text { Ease of } \\
\text { Use }\end{array}$} & $\begin{array}{l}\text { Navigation } \\
\text { and Links }\end{array}$ & Clear navigation & $\begin{array}{l}\text { Only global navigation, } \\
\text { no choices in links, is } \\
\text { difficult to switch }\end{array}$ & $\begin{array}{l}\text { Multi-link options, to } \\
\text { provide global navigation, } \\
\text { local navigation, contextual } \\
\text { navigation, secondary } \\
\text { navigation }\end{array}$ & $\begin{array}{l}\text { Irreversible process } \\
\text { undo problem }\end{array}$ \\
\hline & Page Structure & & $\begin{array}{l}\text { Jump page frequently, } \\
\text { visual fatigue, and only } \\
\text { one active interface }\end{array}$ & $\begin{array}{l}\text { Multi-interface can be } \\
\text { achieved simultaneously, } \\
\text { switch freely }\end{array}$ & \\
\hline & Operability & Strong operational & & & $\begin{array}{l}\text { Poor user experience, } \\
\text { data editing, keyboard } \\
\text { operability need to } \\
\text { be improved }\end{array}$ \\
\hline & Page refresh & Fast, without delay & & & $\begin{array}{l}\text { Refresh overall, low } \\
\text { efficiency, lead to } \\
\text { form Information loss }\end{array}$ \\
\hline \multicolumn{2}{|c|}{ Memo ability } & & No memo ability & $\begin{array}{l}\text { Strong memo ability } \\
\text { with prompts }\end{array}$ & \\
\hline \multirow{2}{*}{$\begin{array}{l}\text { Fault } \\
\text { tolerance }\end{array}$} & $\begin{array}{c}\text { Error } \\
\text { prevention }\end{array}$ & $\begin{array}{l}\text { Verify the } \\
\text { information before } \\
\text { sending }\end{array}$ & & $\begin{array}{l}\text { Verify the information } \\
\text { before sending }\end{array}$ & \\
\hline & Error recovery & $\begin{array}{l}\text { Error message, } \\
\text { error rollback }\end{array}$ & & $\begin{array}{c}\text { Error screen, explain the } \\
\text { reasons for the error and } \\
\text { prompt solutions. }\end{array}$ & \\
\hline $\begin{aligned} & \text { In } \\
& \text { FA }\end{aligned}$ & $\begin{array}{l}\text { activity } \\
\text { eedback }\end{array}$ & With online help & & $\begin{array}{c}\text { can achieve real-time } \\
\text { feedback, and respond } \\
\text { quickly under network } \\
\text { environment }\end{array}$ & \\
\hline & ntent & Content is stable & $\begin{array}{l}\text { The new information } \\
\text { transfer delay }\end{array}$ & $\begin{array}{l}\text { Richer, information updates, } \\
\text { released in a timely manner }\end{array}$ & \\
\hline & nalized & & $\begin{array}{l}\text { Difficult to achieve } \\
\text { personalized }\end{array}$ & Personalized settings & \\
\hline
\end{tabular}

hanced in usability. Asynchronous transfer technology reduced the burden of the server and user s' waiting time, and improved the user experience. They make Webbased information system achieve the same effect as the desktop system.

\subsection{Strategic Partners}

Under supply chain environment, the information will inevitably be shared between enterprises, and JIT requires enterprises to keep delivering information timely and effectively. In the eyes of strategic business partners, IS standards, timely and effectively information transfer are important indicators reflecting the usability. Therefore, the users will concern about the quality and effectiveness of the content. Here, we put forward several proposals:

1) Use common industry terms and abbreviations in IS, help reduce barriers to information exchange, avoid ambiguity.
2) Provide effective interfaces, even the parties are using inconsistent data specification, can realize the automatic data entry and storage.

3) Strictly control the permissions, make users understand the security of system.

\subsection{System Investors}

System investors are the shareholders of enterprises, as investors are more concerned about the interest generated by capital. Putting the realization of management functions aside, IS usability will bring what kind of contribution to corporate earnings. Web information systems' contribution to the business benefits is reflected in the usability advantage of the advocacy role in the enterprise network compared with traditional desktop information system. As rational investors emotional factors have little effect on the usability, they are not satisfied with the basic functions of IS, and they also care about the role of IS to promote the corporate brand and potential business 
gains obtained from it [3]. Web is not just attraction, it is their own best advertisement, and should be able to deliver the brand culture to the users effectively in seconds and result in resonance.

\section{Summary}

An information system is defined as an organization, users achieve their goals by interacting with the IS. High usability brings pleasure to general users, makes employees work smoothly and enables investors to obtain the satisfying potential benefits. On the basis of the scholars' studies about the usability guide and usability evaluation, this article starts from the desired goal of user groups, and IS usability of different models is compared, but still lack the results of data supporting analysis from enterprises. Overall, this article provides comprehensive assist in usability design from multiple perspectives for usability experts and developers in the life cycle of systems development, and can meet the usability needs of all users and lay the foundation for usability evaluation model in the next step.

\section{REFERENCES}

[1] J. Nielsen, "Usability Engineering," Academic Press, Waltham, 1993.

[2] P.-Y. Wu, Q.-L. Tong and Z. Du, "Research and Implementation of Usability Evaluation System of Web Business System," Computer Engineering and Design, Vol. 30, No. 1-2, 2009, p. 338.

[3] R. Agarwal and V. Venkatesh, “Assessing a Firm's Web Presence: A Heuristic Evaluation Procedure for the Measurement of Usability," Information Systems Research,
Vol. 13, No. 2, 2002, pp. 168-186.

[4] J. Nielsen, Ten Usability Heuristics. http://www.useit.com/jakob/

[5] S. Y. Chen and R. D. Macredie, "The Assessment of Usability of Electronic Shopping: A Heuristic Evaluation," International Journal of Information Management, Vol. 25, No. 6, 2005, pp. 516-532. doi:10.1016/j.ijinfomgt.2005.08.008

[6] J. W. Palmer, "Web Site Usability, Design, and Performance Metrics," Information Systems Research, Vol. 13, No. 2, 2002, pp. 151-167.

[7] S. M. Zabed Ahmed, C. McKnight and C. Oppenheim, "A User-Centered Design and Evaluation of IR Interfaces,” Journal of Librarianship and Information Science, Vol. 38, No. 3, 2006, pp. 157-172. doi:10.1177/0961000606063882

[8] F. Calisira and F. Calisir, "The Relation of Interface Usability Characteristics, Perceived Usefulness, and Perceived Ease of Use to End-User Satisfaction with Enterprise Resource Planning (ERP) Systems," Computers in Human Behavior, Vol. 20, No. 4, 2004, pp. 505-515. doi:10.1016/j.chb.2003.10.004

[9] J. M. Pearson and A. Pearson, "Determining the Importance of Key Criteria in Web Usability,” Management Research News, Vol. 30, No. 11, 2007, pp. 816-828. doi:10.1108/01409170710832250

[10] J. Gulliksen, I. Boivie and B. Goransson, "Usability Professionals-Current Practices and Future Development," Interacting with Computers, Vol. 18, No. 4, 2006, pp. 568-600. doi:10.1016/j.intcom.2005.10.005

[11] A. Sutcliffe, "Assessing the Reliability of Heuristic Evaluation for Website Attractiveness and Usability," Proceedings of the 35th Annual Hawaii International Conference on System Sciences (HICSS-35’02), Maui, Vol. 5, 2002, p. 137. 